$$
-15419 \text { - }
$$

\title{
THE EFFECT OF LANDSCAPE PATTERN IN RESPONSE TO ECOLOGICAL ENVIRONMENT AND CLIMATE CHANGE IN XIAOXING'ANLING, HEILONGJIANG PROVINCE, CHINA
}

\author{
GAO, W. $.^{1,2}-$ WAN, L. H. ${ }^{1,2^{*}}-$ DU, Y. X. ${ }^{1,2}-$ ZHU, D. Y. ${ }^{1,2}$ \\ ${ }^{1}$ Heilongjiang Province Key Laboratory of Geographical Environment Monitoring and Spatial \\ Information Service in Cold Regions, Harbin Normal University, Harbin 150025, China \\ ${ }^{2}$ College of Geographical Science, Harbin Normal University, Harbin 150025, China \\ (e-mail:834655281@qq.com,wanluhe@163.com,78862668@qq.com, zhudy0717@163.com) \\ *Corresponding author \\ e-mail: wanluhe@163.com \\ (Received 12 ${ }^{\text {th }}$ Jul 2019; accepted $14^{\text {th }}$ Nov 2019)
}

\begin{abstract}
Wetlands play an important role in conserving water sources, regulating climate, and protecting biodiversity and have extremely high ecological value. However, global natural wetlands are rapidly degrading. Therefore, protecting wetlands is of strategic importance for ensuring ecological and environmental security. Based on the Landsat remote sensing images from 1975 to 2015 and the monthly meteorological data during the same periods, this study analyzed the landscape pattern change and explored the relationship with climate change and wetland change in Xiaoxing'anling, using the methods of landscape ecology and mathematical statistics. The results showed that the degree of landscape fragmentation was unused land < water area $<$ forest land $<$ urban land $<$ cultivated land $<$ wetland and the number of patches had increasing trend. The wetlands were mainly converted into cultivated land and the wetland areas have significantly degraded in the past 40 years in Xiaoxing'anling. The change of landscape diversity had a close correlation with annual precipitation and average summer precipitation. This study provides a theoretical basis for regional wetland protection.
\end{abstract}

Keywords: wetland, cumulative anomaly analysis, canonical correlation analysis, Landsat, transfer matrix

\section{Introduction}

Wetlands have a role in regulating water sources, regulating climate, purifying water quality, protecting species and regional ecological security (Zhu and $\mathrm{Li}, 1996$ ), and significantly affect on economic development, human living environment, and climate change of regionally, and even globally (Liu, 2005). There are many wetlands in Northeast China, but the wetland areas were rapidly declining due to global warming and human activity (Gong et al., 2016). Using remote sensing measures to study wetlands has the advantages of low cost and easy access (Dogan et al., 2009; Lane et al., 2014). The classification methods of wetland include supervised classification, unsupervised classification, object-oriented classification and machine learning classification. Dronova et al. (2011) analyzed wetland classification accuracy by object-oriented and supervised classification methods. Sadeghi et al. (2012) used the support vector machine (SVM) to predict the distribution of invasive water ferns in the Anzhali wetland of Iran.

Wetland landscape has become closely related to many factors such as regional and resource distribution, anti-interference ability, self-recovery and biodiversity, and has become an important research field of landscape ecology (Li and Zeng, 2002). The quantitative method is the main method to study the change of wetland landscape pattern, for example, Fan et al. (2014) analyzed the change characteristics of wetland landscape 
patterns in Nansi Lake of Shandong Province from 1982 to 2012 by landscape pattern index. Wang et al. (2012) compared the wetland landscape pattern changes in different time and space scales in the Yellow River Delta in 2000 and 2009 year from the aspects of landscape area change, landscape patch characteristics and overall landscape pattern. Chen et al. (2006) applied the landscape gradient model to analyze the landscape pattern characteristics of the Xianghai Nature Reserve in different periods. Luo et al. (2015) studied the temporal and spatial change of the landscape pattern of the Kazakhstan Delta through cellular automaton (CA)-Markov model.

In the study, using the Landsat remote sensing data with a 30-m resolution of 1975, 1985, 1995, 2005 and 2015 year and the monthly meteorological data, by the landscape ecology and mathematical statistics methods, we analyzed the landscape pattern change in Xiaoxing'anling. Our aim was to find the correlation between landscape pattern change and climate change in Xiaoxing'anling, and reveal the relationship between landscape pattern change and climate change. The study provides scientific theoretical basis and important guiding significance for landscape protection of Xiaoxing'anling wetland.

\section{Materials and Methods}

\section{Study area}

Xiaoxing'anling lies in the northern part of Heilongjiang Province, where the north and northeast are bounded by the Heilongjiang River, the northwest, the Aihui District of Heihe city and Nenjiang County are connected to Daxinganling, the east is adjacent to the Sanjiang Plain, the southeast is separated from the Zhangguangcai Mountains by the Songhua River Valley, and the southwest is connected to the Nenjiang Plain (Fig. 1).

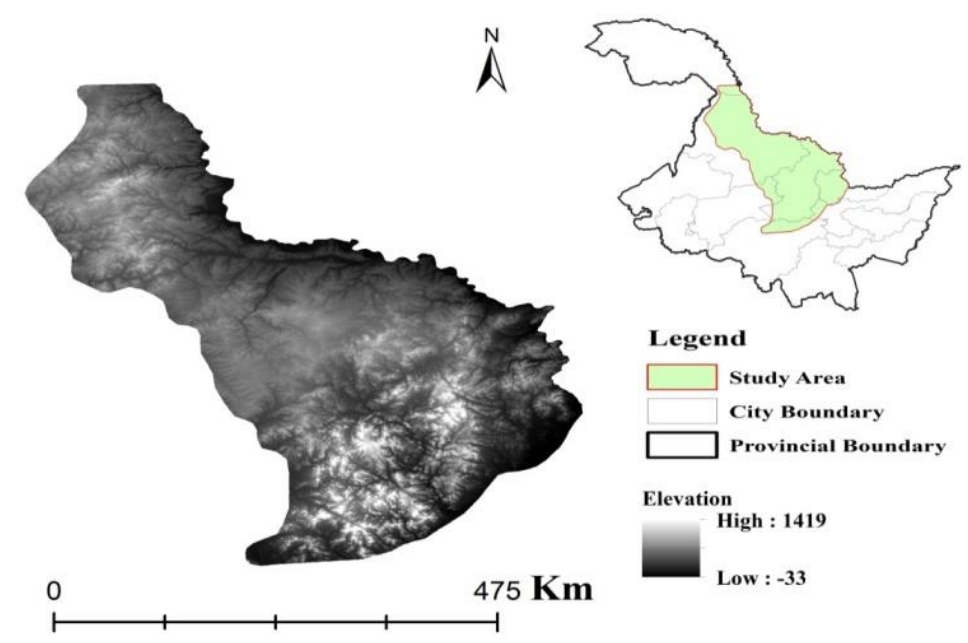

Figure 1. Location and elevation of the study area

The geographical coordinates are $4550^{\prime}-5110^{\prime} \mathrm{N}, 12520^{\prime}-13120^{\prime} \mathrm{E}$ (Liu, 2012). The altitude of the mountain range is approximately 500 800 meters, and the individual peaks are above 1000 meters. The average annual precipitation in the study area is approximately 550 700 $\mathrm{mm}$. This area is one of the most concentrated areas of wetland, with abundant wetland types such as forest swamps, shrub swamps, and herb swamps et al. (Liu, 2012). 


\section{Dataset}

The Landsat remote sensing data with a 30-m resolution of the study were downloaded from https://glovis.usgs.gov/. The images with less 5\% cloud cover from June to August in 1975, 1985, 1995, 2005 and 2015 year were select. Band combination, geometric correction, image mosaic and cropping for every period were completed using ENVI5.1 software. Based on the land use classification standard in China, we collected 1011 training samples from field data (collected using GPS) and classified the land use types as wetland, cultivated land, forest, urban, waters, and unused land using the support vector machine method.

The meteorological data used in the study came from the National Meteorological Information Center (http://www.cma.gov.cn/2011qxfw/2011qsjgx/). We collected the monthly and annual average minimum temperature, average maximum temperature, average temperature, average relative humidity, and precipitation from 1975 to 2015 for in Huma, Aihui, Sunwu, Yichun, Tieli, Hegang, Jiamusi and Yilan eight meteorological stations in Xiaoxing'anling and its surrounding areas.

\section{Methods}

\section{Landscape pattern index}

The landscape pattern index can quantify the complex landscape pattern and its changing process, condensing its information and reflecting its structure and configuration (Peng, 2006). The landscape pattern index that included the number of plaques (NP), percentage of landscape types (PLAND), aggregation index (AI), largest patch index (LPI), plaque density (PD), perimeter area fractal (PAFRAC), Shannon diversity index (SHDI) and Shannon evenness index (SHEI) were used to reflect the size of patches, the fragmentation, and the diversity of landscapes in the study area (Wang et al., 2017; Du et al., 2018; Wu and Li, 2018). The literature described the above eight landscape pattern indices in detail (Li et al., 2016; Ma et al., 2018).

\section{Moving average method}

The moving average method could visually reflect the trend of changes in meteorological sequences and eliminated the effects of sequence fluctuations. In general, a new sequence $\mathrm{y}_{1}$ was obtained by calculating $2 \mathrm{k}$ or $2 \mathrm{k}+1$ continuous averaging in the meteorological sequence $\mathrm{x}_{1}, \mathrm{x}_{2} \ldots \ldots \mathrm{x}_{\mathrm{n}}$. The specific equation was as follows $(\mathrm{Xu}$ et al., 2015).

$$
\mathrm{y}_{1}=\frac{1}{2 \mathrm{k}+1} \sum_{-\mathrm{k}}^{\mathrm{k}} \mathrm{x}_{\mathrm{i}+1}
$$

The trend analysis of the meteorological sequence was calculated using a 5-year moving average in our study $(\mathrm{k}=2)$.

\section{Canonical correlation analysis}

The canonical correlation analysis was used to analyze the correlation between the two groups of variables. The core idea was that the correlations between (the independent variable group and the standard variable group) were indicated by selecting several representative comprehensive indicators from the two sets of random variables. In the study of landscape pattern change, because different landscape types interact and restrict 


$$
-15422 \text { - }
$$

each other, the canonical correlation analysis was often used to analyze the relationship between landscape patterns and various natural and socio-economic drivers (Huang, 2010).

\section{Results}

\section{Land use transfer matrix}

The land use transfer matrix (Table 1) from 1975 to 2015 was obtained using the SVM classification method to classify the remote sensing images in the study area in1975, 1985, 1995, 2005 and 2015 year.

From the perspective of transfer, the land use transfer in the study area was that the forest with the area of $10430.13 \mathrm{~km}^{2}$ was converted into wetland and cultivated land; the wetland with the area of $24706.11 \mathrm{~km}^{2}$ was converted into forest and cultivated land; the cultivated land with the area of $3175.67 \mathrm{~km}^{2}$ was converted into forest and wetland from 1975 to 2015. From the perspective of transition, the changes mainly occurred that the water was mainly converted from forest and wetlands with the area of $302.9 \mathrm{~km}^{2}$; the unused land was mainly converted from wetland, forest and cultivated land with the area of $628.82 \mathrm{~km}^{2}$; urban was mainly converted from wetland, cultivated land and forest with the area of $1022.02 \mathrm{~km}^{2}$. In short, the landscape type transfer in Xiaoxing'anling mainly occurred between cultivated land, forest and wetland.

Table 1. Land use transfer matrix in the study area from 1975 to $2015\left(\mathrm{~km}^{2}\right)$

\begin{tabular}{c|c|c|c|c|c|c}
\hline $\mathbf{1 9 7 5}-\mathbf{2 0 1 5}$ & water & forest & unused land & urban & wetland & cultivated land \\
\hline water & 395.30 & 146.05 & 3.68 & 25.23 & 156.40 & 58.67 \\
forest & 72.48 & 44261.30 & 53.00 & 83.76 & 13713.55 & 2164.02 \\
unused land & 13.78 & 139.10 & 6.58 & 14.70 & 388.56 & 101.16 \\
urban & 27.02 & 296.31 & 10.37 & 138.20 & 417.00 & 309.02 \\
wetland & 59.67 & 5478.66 & 25.30 & 65.74 & 9121.86 & 1011.65 \\
cultivated land & 74.23 & 4951.47 & 83.12 & 270.72 & 10992.56 & 4030.91 \\
\hline
\end{tabular}

\section{Landscape pattern change analysis}

The Landscape pattern index at plaque type level (Table 2) and Landscape pattern index on landscape level (Table 3) in Xiaoxing'anling from 1975 to 2015 year were calculated by Fragstats software.

The number of plaques (NP) increasing and the aggregation index (AI) decreasing from $90.53 \%$ to $84.13 \%$ indicated that the number of plaques increased continuously, and the landscape became more and more fragmented in Xiaoxing'anling from1975 to 2015. At the landscape level, the largest plaque index (LPI) in Xiaoxing'anling decreased from $48.94 \%$ to $16.79 \%$ from 1975 to 2015 , indicating that the maximum plaque area was declined, and the landscape dominance decreases with the decrease of the total area of the landscape. The diversity index in the study area has increased year by year, and the growth trend of uniformity index is consistent with the decreasing trend of landscape dominance difference, indicating that the distribution of landscape elements tends to be balanced. The perimeter area fractal (PAFRAC) first increased and then decreased and 


$$
-15423 \text { - }
$$

the fractal dimension was the largest in 1985 year, indicating that the shape of the plaque in the study area was closer to the square since 1985. It could be inferred that the study area had been disturbed by humans, and was still moving in the direction of increased interference.

Table 2. The landscape pattern index at plaque type level in study area from 1975 to 2015

\begin{tabular}{|c|c|c|c|c|c|c|}
\hline \multirow{2}{*}{ year } & \multirow{2}{*}{ Land use type } & \multicolumn{5}{|c|}{ Plaque type level landscape pattern index } \\
\hline & & NP & PLAND\% & $\mathrm{AI} \%$ & LPI\% & PD \\
\hline \multirow{6}{*}{1975} & cultivated land & 46605 & 3.04 & 80.63 & 1.17 & 0.47 \\
\hline & forest & 38232 & 67.33 & 92.67 & 25.73 & 0.39 \\
\hline & water & 2527 & 0.42 & 78.25 & 0.22 & 0.03 \\
\hline & wetland & 96416 & 28.41 & 81.54 & 10.86 & 0.98 \\
\hline & urban & 70856 & 0.71 & 80.17 & 0.25 & 0.72 \\
\hline & unused land & 1983 & 0.09 & 52.34 & 0.05 & 0.20 \\
\hline \multirow{6}{*}{1985} & cultivated land & 143089 & 3.44 & 82.5 & 1.28 & 1.44 \\
\hline & forest & 40909 & 66.66 & 87.29 & 27.96 & 0.11 \\
\hline & water & 20992 & 0.79 & 72.72 & 0.22 & 0.21 \\
\hline & wetland & 140658 & 28.06 & 80.08 & 10.62 & 1.42 \\
\hline & urban & 76590 & 0.76 & 79.66 & 0.28 & 0.77 \\
\hline & unused land & 6839 & 0.29 & 74.97 & 0.10 & 0.37 \\
\hline \multirow{6}{*}{1995} & cultivated land & 264385 & 13.90 & 87.53 & 5.59 & 1.58 \\
\hline & forest & 53471 & 57.29 & 80.55 & 21.35 & 0.42 \\
\hline & water & 35851 & 0.86 & 76.35 & 0.31 & 0.34 \\
\hline & wetland & 357435 & 26.09 & 77.24 & 10.94 & 3.14 \\
\hline & urban & 79853 & 1.33 & 82.54 & 0.55 & 0.65 \\
\hline & unused land & 8951 & 0.52 & 82.61 & 0.23 & 0.58 \\
\hline \multirow{6}{*}{2005} & cultivated land & 407235 & 17.06 & 92.32 & 7.22 & 1.42 \\
\hline & forest & 59782 & 56.03 & 76.23 & 21.10 & 0.48 \\
\hline & water & 41352 & 0.87 & 76.37 & 0.65 & 0.41 \\
\hline & wetland & 482152 & 23.61 & 76.12 & 8.74 & 4.57 \\
\hline & urban & 83425 & 1.20 & 85.02 & 0.47 & 0.62 \\
\hline & unused land & 11225 & 1.23 & 90.35 & 0.50 & 0.46 \\
\hline \multirow{6}{*}{2015} & cultivated land & 557832 & 13.31 & 95.26 & 4.30 & 1.37 \\
\hline & forest & 65065 & 71.02 & 71.33 & 27.66 & 0.66 \\
\hline & water & 49884 & 0.88 & 76.19 & 0.33 & 0.50 \\
\hline & wetland & 638265 & 12.84 & 72.69 & 4.80 & 6.44 \\
\hline & urban & 85065 & 1.08 & 84.85 & 0.45 & 0.57 \\
\hline & unused land & 13614 & 0.84 & 95.26 & 0.32 & 0.47 \\
\hline
\end{tabular}


Gao et al.: The effect of landscape pattern in response to ecological environment and climate change in Xiaoxing'anling, Heilongjiang Province, China

$$
-15424-
$$

Table 3. The landscape pattern index of the landscape level in study area from 1975 to 2015

\begin{tabular}{c|c|c|c|c|c|c}
\hline \multirow{2}{*}{ year } & \multicolumn{7}{|c}{ landscape pattern index at landscape level } \\
\cline { 2 - 7 } & NP & LPI\% & AI\% & PAFRAC & SHDI & SHEI \\
\hline 1975 & 274469 & 48.94 & 90.53 & 1.40 & 0.97 & 0.54 \\
1985 & 399077 & 38.20 & 87.51 & 1.47 & 0.95 & 0.53 \\
1995 & 753562 & 33.48 & 88.73 & 1.38 & 0.98 & 0.55 \\
2005 & 1052345 & 20.56 & 86.54 & 1.32 & 1.02 & 0.57 \\
2015 & 1464177 & 16.79 & 84.13 & 1.34 & 1.05 & 0.58 \\
\hline
\end{tabular}

Note: The meanings of the abbreviation of the captions in the Table 3 are as follows: PAFRAC - perimeter area fractal, SHDI - Shannon's diversity index, SHEI - Shannon's evenness index

\section{Climate change analysis}

The climatic characteristics were represented by the annual climatic data of the eight meteorological stations for 40 years. The climate change trend was shown in Fig. 2. The annual relative humidity in Xiaoxing'anling was decreasing and annual decrease rate was $0.0174 \%$. The annual precipitation in Xiaoxing'anling showed an increase trend with the rate $1.59 \mathrm{~mm}$ and passed 0.1 . significance level test $(\mathrm{p}<0.1)$.

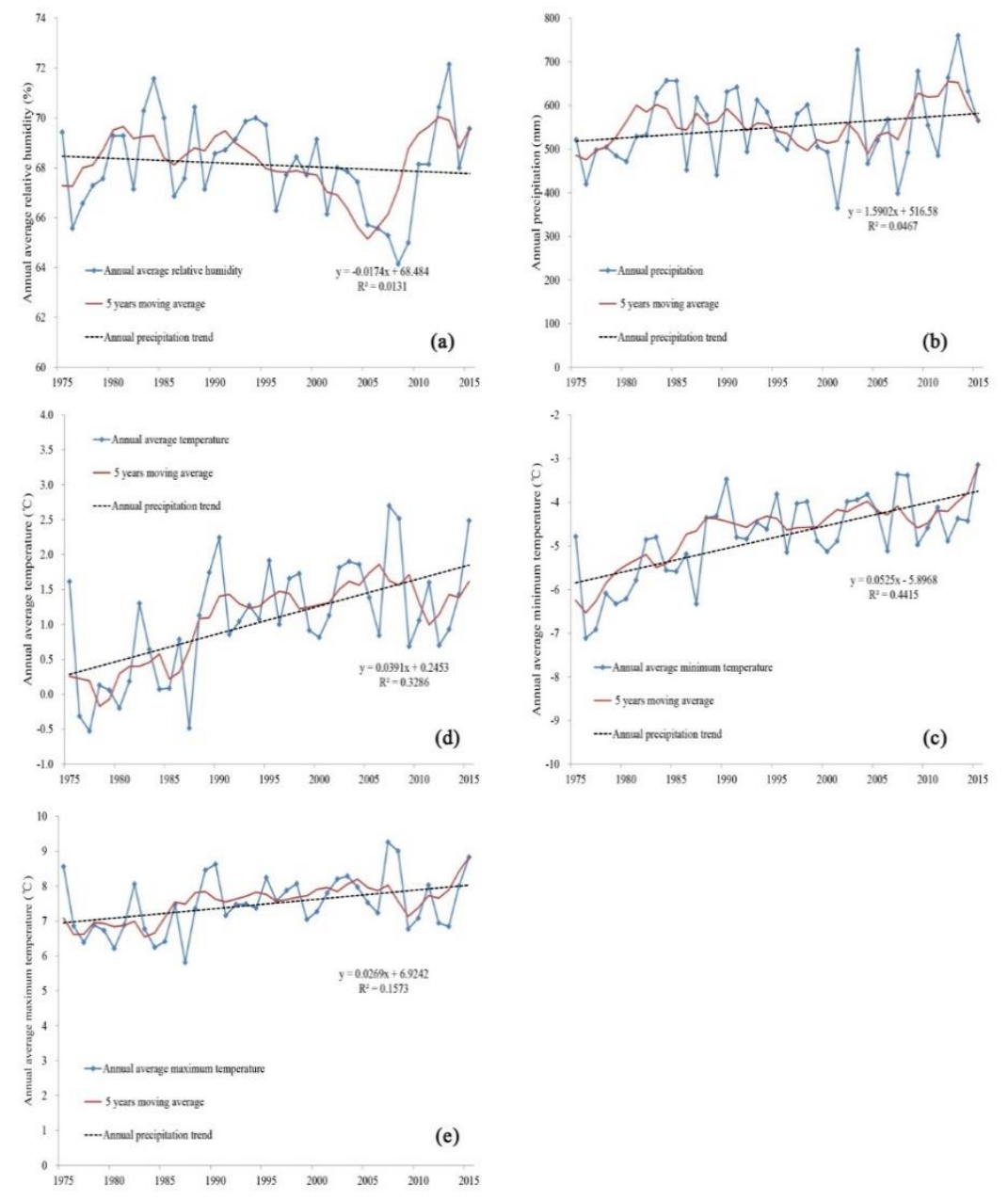

Figure 2. Climate trend analyzing in Xiaoxing'anling from 1975 to 2015 
The trends of annual average temperature, annual average minimum temperature and annual average maximum temperature in Xiaoxing'anling had increased, and the increasing rates were $0.39^{\circ} \mathrm{C} / 10 \mathrm{a}, 0.525^{\circ} \mathrm{C} / 10 \mathrm{a}$ and $0.27^{\circ} \mathrm{C} / 10 \mathrm{a}$, respectively, which passed 0.05 significance level test $(\mathrm{p}<0.05)$. The annual warming trend of the study area was synchronized with the background of continuous warming since the $1950 \mathrm{~s}$ in the Northeast, and the growth rate of the annual average minimum temperature was higher than the annual average maximum temperature and the annual average temperature, so the temperature was more affected by the increase in the annual average minimum temperature.

By monthly data, the average temperature and precipitation data of spring (MarchMay), summer (June-August), autumn (September-November) and winter (DecemberFebruary) are counted. 5 years moving average seasonal and annual climatic factors were obtained in Fig. 3.
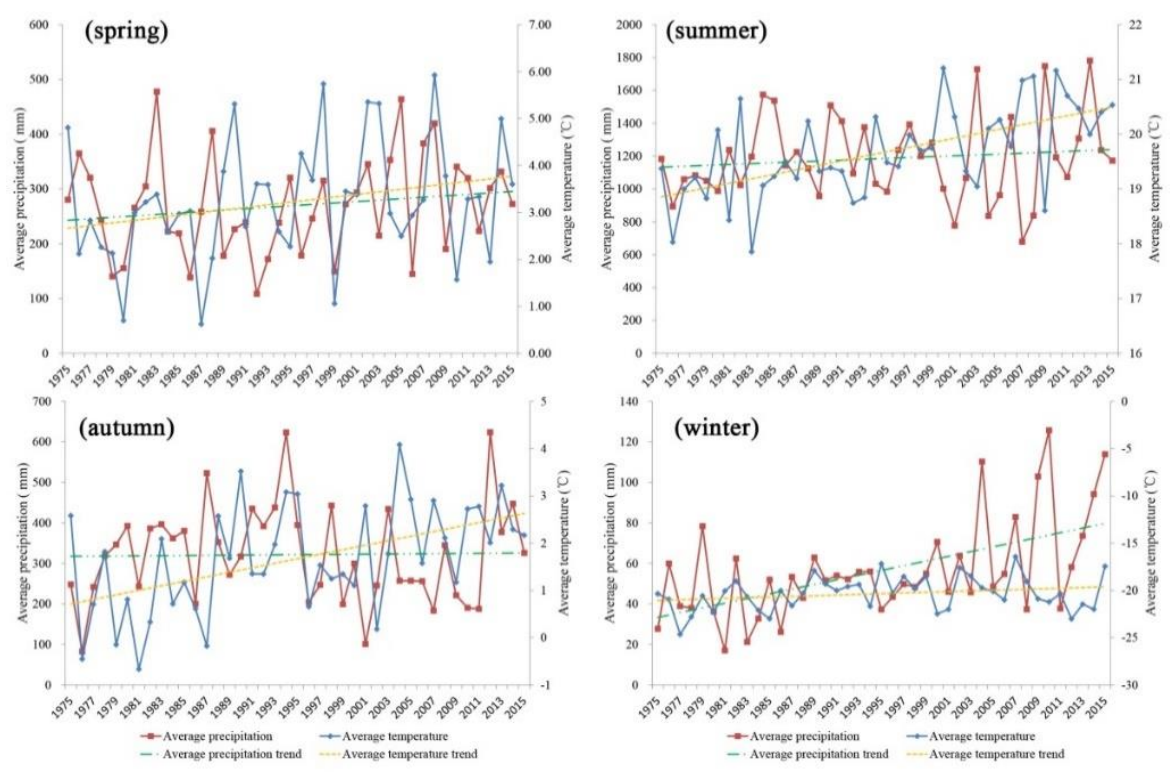

Figure 3. Climatic trend in each quarter from 1975 to 2015

From 1975 to 2015, the temperature and precipitation in the Xiaoxing'anling showed an upward trend, and the increase rates of the temperature from spring to winter were $0.28 / 10 \mathrm{a}, 0.41^{\circ} \mathrm{C} / 10 \mathrm{a}, 0.48^{\circ} \mathrm{C} / 10 \mathrm{a}$ and $0.35^{\circ} \mathrm{C} / 10 \mathrm{a}$, respectively. In addition, the average temperature in summer and autumn passed the 0.05 significance level test $(\mathrm{p}<0.05)$. The change rates of precipitation from spring to winter were $13.09 \mathrm{~mm} / 10 \mathrm{a}, 26.45 \mathrm{~mm} / 10 \mathrm{a}$, $18.9 \mathrm{~mm} / 10 \mathrm{a}$ and $15.96 \mathrm{~mm} / 10 \mathrm{a}$, respectively. Although the seasonal precipitation was on the rise, only the precipitation trend passed the 0.05 significance level $(p<0.05)$ in winter.

\section{Response relationship between climate change and wetland landscape pattern change}

According to the basic data and our research purpose, the analysis results with confidence greater than $95 \%(\mathrm{p}<0.05)$ were used for all correlation coefficients. The canonical correlation analysis result of wetlands was shown in Table 4. There was a typical correlation coefficient of 0.881 , and the statistical test reached a significant level, 
so the first pair of typical variables was selected for analysis. According to Fig. 4, the first linear combination (canonical) of the climatic factor variables was x2 (annual precipitation) and $\mathrm{x} 9$ (summer average precipitation), and canonical variables for maximum correlation were y1 (NP) and y5 (PD). There was a close correlation between the annual precipitation and the average summer precipitation and the wetland landscape fragmentation index. From 1975 to 1985 year, the annual precipitation decreased first and then increased, the wetland areas decreased and the change was the smallest in the five periods. However, from 1995 to 2005 year, the annual precipitation decreased continuously, the wetland areas decreased and the landscape fragmentation increased sharply. It was concluded that due to the change of annual precipitation, it was likely to cause changes in the wetland areas at the same time and thus the change of landscape fragmentation.

Table 4. Canonical correlation coefficient

\begin{tabular}{c|c|c|c|c}
\hline Typical variables & Canonical Correlations & Chi-SQ & DF & Sig \\
\hline 1 & 0.881 & 111.088 & 65.000 & 0.000 \\
2 & 0.791 & 65.337 & 48.000 & 0.249 \\
3 & 0.709 & 35.326 & 33.000 & 0.359 \\
4 & 0.527 & 13.979 & 20.000 & 0.832 \\
5 & 0.353 & 4.062 & 9.000 & 0.907 \\
\hline
\end{tabular}

Note: Chi-SQ refers to chi square statistic, DF is degree of freedom and Sig is significant level

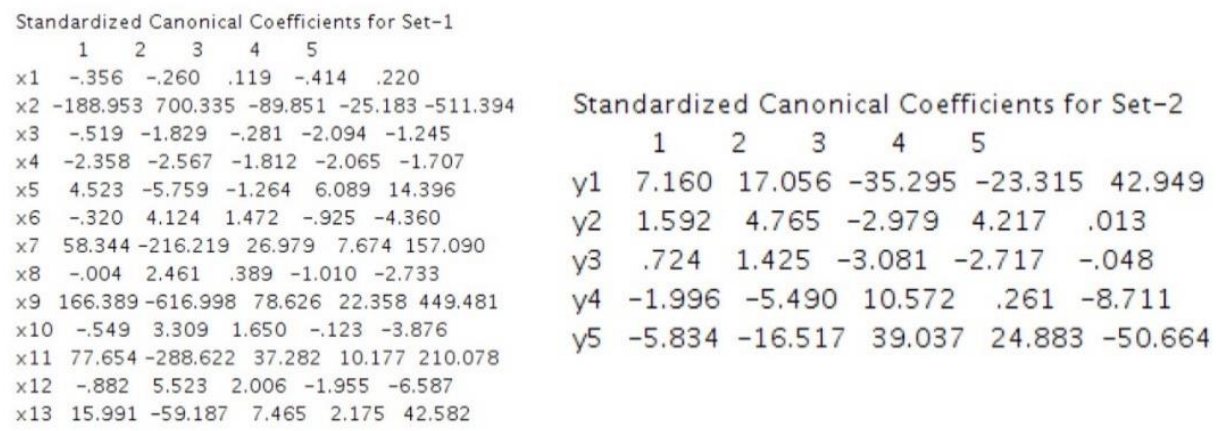

Figure 4. Standardized canonical coefficients

Note: $x 1$ - annual relative humidity; $x 2$ - annual precipitation; $x 3$ - annual minimum temperature; $x 4$ - annual maximum temperature; $x 5$ - annual average temperature; $x 6$ - average spring temperature; $x 7$ - average spring precipitation; $x 8$ - average summer temperature; $x 9$-average summer precipitation; $x 10$ - average autumn temperature; $x 11$ - average autumn precipitation; x12-average winter temperature; $x 13$ - average winter precipitation; $y 1-N P ; y 2-P L A N D ; y 3-$ $A I ; y 4-L P I ; y 5-P D$

\section{Discussion}

Previous studies showed that climate change and the human activities played a key role in the fragmentation of wetland landscapes (Xiao et al., 2010; Hu et al., 2015; Cong et al., 2019). Our findings are similar to the above studies. From 1975 to 2015, the areas of forest and wetland accounted for the largest proportion and they were the type of 


$$
-15427 \text { - }
$$

substrate landscape in Xiaoxing'anling. However, the proportion of cultivated land and urban was gradually increasing, indicating that the wetland degradation trend in Xiaoxing'anling was obvious. The wetland change in Xiaoxing'anling was consistent with the shrinking trend of wetland in Northeast China (Gao et al., 2018; Yu et al., 2018). The landscape type transfer in Xiaoxing'anling mainly occurred between cultivated land, forest and wetland. At the plaque level, the wetland landscape dominance continued to decline significantly from 1975 to 2015 , the dominant degree of forest land decreased first and then increased, and the dominance of cultivated land gradually increased. The overall dominance trend of each landscape type tended to balance development; the landscape fragmentation degree of Xiaoxing'anling was ranked as unused land $<$ water area $<$ forest land < urban land < cultivated land < wetland.

At the landscape level, the NP value had increased year by year from 1975 to 2015 , and the number of patches in Xiaoxing'anling has been increasing, indicating the landscape of the whole study area has become more and more fragmented. The AI and the largest plaque index (LPI) decreased from $90.53 \%$ to $84.13 \%$ and from $48.94 \%$ to $16.79 \%$ during 1975 - 2015 year respectively, indicating the diversity index increasing. The fractal dimension was the largest in 1985, indicating that the study area was interfered with human activities and the interference had been larger and stronger since 1985.

In the past 40 years, the annual minimum temperature, annual maximum temperature and annual average temperature in Xiaoxing'anling had increased significantly. The wetlands in the study area were significantly correlated with annual precipitation and average summer precipitation. The landscape level had the greatest correlation with climate change factors. Typical variables were PAFRAC and SHEI. The change of landscape diversity of Xiaoxing'anling wetland had a close correlation with annual precipitation and average summer precipitation.

\section{Conclusions}

Based on Landsat images and meteorological data, using landscape ecology and mathematical statistics methods, the changes of landscape pattern of wetland and response of climate change on landscape pattern change in Xiaoxing'anling were analyzed. The results showed that substrate landscapes in Xiaoxing'anling were forest and wetland, but the proportion of cultivated and urban was gradually increasing; the landscape type transfer in Xiaoxing'anling mainly occurred between cultivated land, forest and wetland; and the wetland degradation trend was obvious. The landscape fragmentation ranking was unused land < water area < forest land < urban land < cultivated land < wetland. At the landscapelevel, the number of patches and diversity index in Xiaoxing'anling were increasing year by year. The wetlands in the study area were significantly correlated with annual precipitation and average summer precipitation. The landscape level had the greatest correlation with climate change factors. The canonical variables were PAFRAC and SHEI. The change of landscape diversity of Xiaoxing'anling had a close correlation with annual precipitation and average summer precipitation. This paper revealed the response of landscape pattern change to climate change macroscopically from 1975 to 2015 in Xiaoxing'anling. We will furtherly research the driving mechanism of landscape pattern change in the future, and provide scientific basis for wetland planning and protection. 


$$
-15428 \text { - }
$$

Acknowledgments. The study was supported by The National Natural Science Foundation of China (No.41671100).

\section{REFERENCES}

[1] Chen, M., Wang, Z. M., Zhang, S. Q., Zhang, B., Li, X. F., Ren, C. Y. (2006): Study on the variation of landscape pattern and the gradient distribution of wetland in the Xianghai Nature Reserve. - Arid Land Geography 05: 694-699. [in Chinese].

[2] Cong, P., Chen, K., Qu, L., Han, J. (2019): Dynamic Changes in the Wetland Landscape Pattern of the Yellow River Delta from 1976 to 2016 Based on Satellite Data. - Chinese Geographical Science 29(3): 372-381.

[3] Dogan, O. K., Akyurek, Z., Beklioglu, M. (2009): Identification and mapping of submerged plants in a shallow lake using quickbird satellite data. - Journal of Environmental Management 90(7): 2138-2143.

[4] Dronova, I., Peng, G., Wang, L. (2011): Object-based analysis and change detection of major wetland cover types and their classification uncertainty during the low water period at Poyang Lake, China. - Remote Sensing of Environment 115(12): 3220-3236.

[5] Du, J. L., Zhu, J. W., Xie, J. C., Ma, Z. H. (2018): Changes of land use and landscape pattern in the Guanzhong area in recent 25 years. - Arid Zone Research 35(01): 217-226. [in Chinese].

[6] Fan, Q., Du, T., Yang, J., Xi, J. C., Li, X. M., Chen, P. (2014): Landscape pattern changes for Nansihu wetland from 1982 to 2012. - Resources Science 36(4): 865-873. [in Chinese].

[7] Gao, C. Y., Zhang, S. Q., Liu, H. X., Cong, J. X., Li, Y. H., Wang, G. P. (2018): The impacts of land reclamation on the accumulation of key elements in wetland ecosystems in the Sanjiang Plain, northeast China. - Environmental Pollution 237.

[8] Gong, N., Niu, Z. G., Qi, W., Zhang, H. Y. (2016): Driving forces of wetland change in China. - Journal of Remote Sensing 20(2): 172-183. [in Chinese].

[9] Hu, Y., Huang, J., Du, Y., Han, P., Huang, W. (2015): Monitoring spatial and temporal dynamics of flood regimes and their relation to wetland landscape patterns in Dongting Lake from MODIS time-series imagery. - Remote Sensing 38(6): 7494-7520.

[10] Huang, C. (2010): Analysis of the relationship between landscape pattern change and climate factors in Karamay Plantation area. - Xinjiang University. [in Chinese].

[11] Lan, Y. C., Liu, G. S., La, C. F., Zhu, Y. T., Ma, Q. J., Shi, M. X. (2017): Study on the characteristics and trend of runoff change in the source region of the Yellow River and its regional difference. - Journal of Mountain Science 35(03): 257-265. [in Chinese].

[12] Lane, C. R., Anenkhonov, O., Liu, H., Autrey, B. C., Chepinoga, V. (2014): Classification and inventory of freshwater wetlands and aquatic habitats in the Selenga river delta of lake Baikal, Russia, using high-resolution satellite imagery. - Wetlands Ecology \& Management 23(2): 1-20.

[13] Li, S. J., Zeng, H. (2002): The utilities of remote sensing technique in landscape study. Journal of Remote Sensing 6(3): 233-240. [in Chinese].

[14] Li, M. Y., Xing, Y. Q., Wang, Z., Liu, M. S., Yao, S. T., Xie, J., Zeng, X. J. (2016): Changes of land coverage and land use in the Wangqing County based on RS and GIS. - Journal of Northwest Forestry University 31(06): 257-263. [in Chinese].

[15] Liu, H. Y. (2005): Characteristics of wetland resources and ecological safety in China. Resources Science (03): 54-60. [in Chinese].

[16] Liu, L. X. (2012): Study on the plant biodiversity and ecosystem service functions evaluation of forest ecosystem in Xiaoxing'an Mountains. - Northeast Forestry University 9-13. [in Chinese].

[17] Luo, G., Amuti, T., Zhu, L., Mambetov, B. T., Maisupova, B., Zhang, C. (2015): Dynamics of landscape patterns in an inland river delta of eentral asia based on a cellular automataMarkov model. - Regional Environmental Change 15(2): 277-289. 
[18] Ma, B. R., Ma, A. Q., Yu, X. X., Hu, J., Xing, R. R. (2018): Analysis on dynamic characteristics in the wetlands of Ziya river basin. - Periodical of Ocean University of China 48(09): 108-117. [in Chinese].

[19] Peng, W. C. (2006): Study of EUO-tourism developing strategy in Hei Longjiang province. - Northeast Normal University. [in Chinese].

[20] Sadeghi, R., Zarkami, R., Sabetraftar, K., Damme, P. V. (2012): Use of support vector machines (SVMs) to predict distribution of an invasive water fern Azolla filiculoides (Lam.) in Anzali wetland, southern Caspian Sea, Iran. - Ecological Modelling 244: 117126.

[21] Wang, Y. L., Yu, J. B., Dong, H. F., Li, Y. Z., Zhou, D., Fu, Y. Q., Han, G. X., Mao, P. L. (2012): Spatial evolution of landscape pattern of coastal wetlands in Yellow river delta. Scientia Geographica Sinica 32(6): 717-724. [in Chinese].

[22] Wang, Y., Liu, C. L., He, P. (2017): Landscape pattern analysis based on GIS and landscape index in Huanghua city. - Journal of Anhui Agricultural Sciences 45(16): 63-67. [in Chinese].

[23] Wu, H. Y., Li, K. G. (2018): Changes of Land Use and Landscape Pattern in Beidaihe District of Qinhuangdao City. - Geospatial Information 16(01): 91-93+106+9. [in Chinese].

[24] Xiao, D. R., Tian, B., Tian, K., Yang, Y. (2010): Landscape patterns and their changes in Sichuan Ruoergai wetland national nature reserve. - Acta Ecologica Sinica 30(1): 27-32.

[25] Xu, T., Shao, H., Zhang, C. (2015): Temporal pattern analysis of air temperature change in Central Asia during 1980-2011. - Arid Land Geography 38(01): 25-35. [in Chinese].

[26] Yu, X. F., Ding, S. S., Zou, Y. C., Xue, Z. S., Lyu, X. G., Wang, G. P. (2018): Review of rapid transformation of floodplain wetlands in northeast China: roles of human development and global environmental change. - Chinese Geographical Science 28(4): 654-664.

[27] Zhu, J. G., Li, Y. Z. (1996): Review of research on wetland in China. - Journal of China Agricultural Resources and Regional Planning (2): 21-24. [in Chinese]. 